\title{
A Comparative Study of Once Daily versus Twice Daily Tacrolimus in Liver Transplantation
}

\author{
Shamilin Stephen ${ }^{1}$, Ranju Markkassery' ${ }^{1}$ Bismi Edathuruthil Sainudheen ${ }^{1}$, Merin Babu' ${ }^{1}$ Dinesh Balakrishnan ${ }^{2}$, Sudhindran Surendran ${ }^{2}$, \\ Uma Devi Padma ${ }^{1 *}$ \\ ${ }^{1}$ Amrita School of Pharmacy, Amrita University, Kochi - 682041, Kerala, INDIA \\ 2Department of Gastrointestinal Surgery, Amrita Institute of Medical Sciences, Amrita University, Kochi - 682041, Kerala, INDIA.
}

\begin{abstract}
Background:Oncedaily (OD) tacrolimus, recentlylaunchedforpostlivertransplantimmunosuppressionmightofferbettercomplianceandefficacycompared to standard twice daily (BID) tacrolimus. Data from India, however is sparse. Aim: The aim of our study was to compare the efficacy and adverse effects of OD versus BID tacrolimus formulation in liver transplant recipients. Methods: This was a retrospective, observational, comparative study of 115 patients who were on tacrolimus based regimens (tacrolimus BID: 92; M: F-75:17 and tacrolimus OD: 23; M: F-22:1). Total daily dose and trough levels of tacrolimus were recorded at 1, 3, 6, 12 and 24 months after transplantation. Results: Median age in tacrolimus BID and OD groups were 45 years (6-64 years) and 50 years (1-70 years), respectively. The median tacrolimus dose was significantly lower in the tacrolimus OD arm at all the time points studied. Tacrolimus trough levels were significantly lower in the tacrolimus OD group at 3 and 6 months. The biopsy proven rejection rate was $15.2 \%$ and $0 \%$ in the tacrolimus BID and OD groups, respectively. Two year patient and graft survival rate was $89.4 \%$ in the tacrolimus BID and $87.5 \%$ in the tacrolimus OD group. The incidence of new onset diabetes,
\end{abstract}

renal dysfunction, dyslipidemia, neurotoxicity, hyperkalemia and weight gain were comparable between the two arms. Conclusion: Tacrolimus OD has a lower rejection rate compared to its BID formulation. However, this does not translate into better patient or graft survival. Both the formulations appear to be comparable with respect to the adverse effect and tolerability profile.

Key words: Biopsy Proven Acute Rejection, Graft Survival, Patient Survival, Liver Transplantation, Tacrolimus Once Daily, Tacrolimus Twice Daily.

Correspondence :

Dr. Uma Devi P, Associate Professor, Department of Pharmacology, Amrita School of Pharmacy, Amrita University, Kochi - 682041, Kerala, India

Phone: 9567700685

Email: umadevip@aims.amrita.edu; umadeviaims@gmail.com

DOI: 10.5530/jyp.2017.9.115

\section{INTRODUCTION}

Liver transplantation is currently the sole choice for patients with end stage decompensated liver disease of chronic and acute aetiology. ${ }^{1,2}$ Being an allogeneic graft, lifelong immunosuppression is essential to avoid liver graft rejection. However, long term immunosuppression is associated with a number of adverse effects such as infections, malignancy and other drug specific issues, which are often dose dependent. ${ }^{3}$ As the window between under and over immunosuppression is narrow, therapeutic drug monitoring of immunosuppressant level is routinely performed to facilitate appropriate dosing. Nevertheless, maintaining optimal immunosuppression is often difficult and considered to be an art. $^{4}$

Tacrolimus, a calcineurin-inhibitor is an important component of the immunosuppressive regimens employed following liver transplantation. It is usually used in combination with antiproliferative agents with or without corticosteroids. Tacrolimus has a narrow therapeutic window and the optimal drug level following liver transplantation is $5-15 \mathrm{ng} / \mathrm{ml}$. The standard preparation of tacrolimus is administered twice daily (BID). ${ }^{5}$ Lifelong consumption, day in day out, every 12 hours requires stringent discipline and could be demanding particularly in adolescent population. In fact, non-adherence with regular tacrolimus consumption has been a problem in western countries. ${ }^{6}$ Furthermore, tacrolimus use is associated with a number of adverse effects including nephrotoxicity, neurotoxicity, new onset diabetes, hyperkalemia, hypertension, hyperlipidemia, hypomagnesemia and hyperuricemia. A new formulation of tacrolimus i.e., tacrolimus extended release can be dosed once daily
$(\mathrm{OD})^{7}$ and may have the ability to simplify immunosuppressive regimens, improve medication compliance and long term allograft survival. ${ }^{8}$ Twice daily tacrolimus results in two peaks in the drug level immediately after consumption followed by tapering over the next 12 hours. However, tacrolimus OD produces lower peak yet a sustained concentration. The pharmacokinetics of tacrolimus BID varies considerably between patients and even within one individual depending on food intake and other medications. It is claimed that pharmacokinetics of tacrolimus OD allows for a more uniform drug level throughout its action of 24 hours thereby producing better efficacy and diminished adverse effects. ${ }^{9}$

Although there are studies comparing the effectiveness and safety of the different tacrolimus formulations, ${ }^{10-12}$ data from India is sparse. The present study has been designed to compare the safety and effectiveness of tacrolimus BID and OD formulations following liver transplantation at our hospital.

\section{MATERIALS AND METHODS}

This study was conducted at the Gastrointestinal Surgery department of Amrita Institute of Medical Sciences. Patients of either sex who had undergone liver transplantation between January 2012 and July 2015 and who were started on either tacrolimus BID or OD were included in the study. The selection between OD or BID tacrolimus was a personal preference, often dictated by the patients' fiscal capability. The cost of $0.5 \mathrm{mg}$ of tacrolimus BID is Rs 21 while the cost of equivalent dosage of tacrolimus OD is Rs 59.5. Along with tacrolimus, our protocol included 
mycophenolate and steroids. Steroids would be normally tapered and stopped within 3 months. Mycophenolate is maintained for 3 months after which its dose is reduced and finally withdrawn by 6 to 9 months. Any alteration in liver function test with suspicion of rejection would be biopsied for confirmation. If there was, delay in resolution of liver function following standard acute cellular rejection (pulsed methyl prednisolone), additional immunosuppression, either mycophenolate or steroid would be continued for longer periods. Patients who died within 1 month of transplantation were excluded. This was an observational study and patient data relevant to the study was collected retrospectively from patient files and hospital health information system. The study was approved by the Institutional Research Committee.

The baseline demographics, aetiology, co-morbidities, body mass index (BMI) and model for end stage liver disease (MELD) scores of the recipients were recorded. Donor details like gender, living/deceased, $\mathrm{ABO}$ compatibility and relationship to recipient were also recorded. Total daily dose and trough levels of tacrolimus were recorded at 1, 3, 6, 12 and 24 months following liver transplantation. In addition, incidence of biopsy proven acute rejection (BPAR), new onset diabetes mellitus, dyslipidemia, neurotoxicity, increase in serum creatinine, hyperkalemia and weight gain were also recorded. Rejection was defined according to the Banff criteria on liver biopsy. ${ }^{13}$ The number of immunosuppressive therapies received by the patient at discharge, 1, 3, 6, 12 and 24 months was also recorded.

Continuous variables were described with mean, median, standard deviation or ranges. Categorical variables were tabulated and expressed as percentage. Continuous variables were compared using Mann Whitney $\mathrm{U}$ test while for categorical variables Chi square test was used. $\mathrm{P}<0.05$ was considered significant. All statistical analyses were carried out with Graph Pad Prism software.

\section{RESULTS}

In the present study, 115 patients who received tacrolimus formulations following liver transplantation were analysed. Out of this population, 92 patients received tacrolimus BID based regimens whilst 23 patients received tacrolimus OD based regimens. The median age in tacrolimus BID and OD groups were 45 years (6-64 years) and 50 years (1-70 years), respectively. Recipient demographics of BID and OD tacrolimus are given in Table 1. In both the treatment groups, majority of the patients were in the age group of $41-60$ years (65.2\% and 52.2\% in the tacrolimus BID and OD groups, respectively). However, the tacrolimus OD group had a significantly higher proportion of patients aged $>60$ years $(30.4 \%)$ compared to tacrolimus BID group $(3.3 \%)[\mathrm{P}<0.0001]$. A significantly higher proportion of patients $(30.4 \%)$ in the tacrolimus OD group suffered from hepatocellular carcinoma compared to the tacrolimus BID group (5.4\%) $[\mathrm{P}=0.0005]$. The two treatment groups were comparable with respect to BMI, MELD scores and co-morbidities.

With respect to the donor demographics, the details are shown in Table 2. Majority of the patients in both the treatment groups underwent ABO compatible transplantation. ABO incompatible transplantation was performed in 3 patients in the tacrolimus BID group. In addition to the standard immunosuppressive regimen, these patients received rituximab and plasmapheresis. Majority of the patients received a right hepatic lobe graft $(88 \%$ and $78.3 \%$ in the tacrolimus BID and OD groups, respectively).

At different time points during the course of the study, both the groups were comparable with respect to the number of immunosuppressive therapies received by the patients. A trend towards a decrease in the number of immunosuppressive therapies was observed as the time from transplantation increased (Table 3 ). At the time of discharge, majority of the patients in the tacrolimus BID group (93.5\%) and all the patients in the tacrolimus OD group were on triple drug therapy. At the end of 12 months following transplantation, $60 \%$ and $80 \%$ patients in the tacrolimus BID and tacrolimus OD groups, respectively were on monotherapy. Similarly, at the end of 24 months following transplantation, majority of the patients in both the treatment groups $(72.9 \%$ and $66.7 \%$ in the tacrolimus BID and OD groups, respectively) were on monotherapy.

The median daily tacrolimus dose at 1 month was $3 \mathrm{mg}$ in the tacrolimus BID group and $2 \mathrm{mg}$ in the tacrolimus OD group. At 24 months after transplantation, the median daily tacrolimus dose was $3 \mathrm{mg}$ in the tacrolimus BID group and $1.5 \mathrm{mg}$ in the tacrolimus OD group. Median daily tacrolimus dose was significantly lower in the tacrolimus OD group compared to the tacrolimus BID group at all the time point studied (Table 4).

Table 1: Patient demographic and clinical characteristics.

\begin{tabular}{|c|c|c|c|}
\hline Characteristics & $\begin{array}{l}\text { Tacrolimus } \\
\text { BID }(\mathrm{N}=92)\end{array}$ & $\begin{array}{l}\text { Tacrolimus } \\
\mathrm{OD}(\mathrm{N}=23)\end{array}$ & P-value \\
\hline \multicolumn{4}{|l|}{ Gender } \\
\hline Male & $75(81.5)$ & $22(95.7)$ & 0.0953 \\
\hline \multicolumn{4}{|l|}{ Age (Years) } \\
\hline$<18$ & $8(8.7)$ & $1(4.3)$ & 0.4874 \\
\hline $18-40$ & $21(22.8)$ & $3(13)$ & 0.3018 \\
\hline $41-60$ & $60(65.2)$ & $12(52.2)$ & 0.2475 \\
\hline$>60$ & $3(3.3)$ & $7(30.4)$ & $<0.0001$ \\
\hline Mean (SD) & $42.9(13.27)$ & $48.6(16.62)$ & 0.0326 \\
\hline \multicolumn{4}{|l|}{ Body mass index } \\
\hline Mean (SD) & $24.3(5.32)$ & $23.9(3.59)$ & 0.8802 \\
\hline \multicolumn{4}{|l|}{ Aetiology } \\
\hline Alcoholic cirrhosis & $37(40.2)$ & $9(39.1)$ & 0.9242 \\
\hline Cryptogenic & $23(25)$ & $4(17.4)$ & 0.4413 \\
\hline Fulminant hepatic failure & $12(13)$ & $2(8.7)$ & 0.5684 \\
\hline Autoimmune & $1(1.1)$ & 0 & 0.6155 \\
\hline Hepatocellular carcinoma & $5(5.4)$ & $7(30.4)$ & 0.0005 \\
\hline Wilson's disease & $2(2.2)$ & 0 & 0.4756 \\
\hline HBV related cirrhosis & $9(9.8)$ & 0 & 0.1182 \\
\hline $\mathrm{HCV}$ related cirrhosis & $2(2.2)$ & 0 & 0.4756 \\
\hline Biliary atresia & $1(1.1)$ & $1(4.3)$ & 0.2846 \\
\hline Byler's disease & $1(1.1)$ & 0 & 0.6155 \\
\hline $\begin{array}{l}\text { Cholestatic disease; Vanishing } \\
\text { bile duct syndrome }\end{array}$ & $1(1.1)$ & 0 & 0.6155 \\
\hline Primary sclerosing cholangitis & $1(1.1)$ & 0 & 0.6155 \\
\hline \multicolumn{4}{|l|}{ MELD Scores } \\
\hline Mean (SD) & $22(5.8)$ & $22.4(8.2)$ & 0.5630 \\
\hline \multicolumn{4}{|l|}{ Co-morbid conditions } \\
\hline Diabetes mellitus & $44(47.8)$ & $11(47.8)$ & 1.0 \\
\hline Hypertension & $12(13)$ & $6(26.1)$ & 0.1236 \\
\hline Dyslipidemia & $1(1.1)$ & 0 & 0.6155 \\
\hline Others & $3(3.3)$ & $2(8.7)$ & 0.2530 \\
\hline
\end{tabular}

$\mathrm{BID}=$ twice daily, $\mathrm{HBV}=$ hepatitis $\mathrm{B}$ virus, $\mathrm{HCV}=$ hepatitis $\mathrm{C}$ virus, $\mathrm{MELD}=$ model for end stage liver disease, $\mathrm{N}=$ number of patients, $\mathrm{OD}=$ once daily, $\mathrm{SD}=$ standard deviation. 
Table 2: Donor characteristics.

\begin{tabular}{cccc}
\hline Characteristics & $\begin{array}{c}\text { Tacrolimus BID } \\
(\mathrm{N}=92)\end{array}$ & $\begin{array}{c}\text { Tacrolimus } \\
\text { OD }(\mathrm{N}=23)\end{array}$ & P-value \\
\hline Gender & $66(71.7)$ & $20(86.9)$ & 0.1328 \\
\hline Female & & & \\
Donor type & $88(95.7)$ & $21(91.3)$ & 0.4017 \\
Living & & & \\
ABO compatibility & $86(93.5)$ & $22(95.7)$ & 0.6631 \\
Compatible & $3(3.3)$ & 0 & \\
Incompatible & $3(3.3)$ & $1(4.3)$ & \\
Unknown & & & \\
Relationship to recipient & $37(40.2)$ & $9(39.1)$ & \\
\hline Spouse & $21(22.8)$ & $2(8.7)$ & \\
Sibling & $12(13)$ & $2(8.7)$ & \\
Parent & $10(10.9)$ & $1(4.3)$ & \\
Child & $6(6.5)$ & $6(26.1)$ & \\
Others & $5(5.4)$ & $2(8.7)$ & \\
Unknown & $1(1.1)$ & $1(4.3)$ & \\
Grandparent & & & \\
\hline
\end{tabular}

$\mathrm{BID}=$ twice daily, $\mathrm{N}=$ number of patients, $\mathrm{OD}=$ once daily. The values represent number of patients (\%)

Table 3: Number of immunosuppressive therapies

\begin{tabular}{cccccc} 
& N & Tacrolimus BID & N & Tacrolimus OD & P-value \\
\hline Discharge & 92 & $3(2-4)$ & 23 & $3(3-3)$ & 0.4089 \\
1 Month & 92 & $3(2-4)$ & 23 & $3(2-3)$ & 0.4479 \\
3 Months & 89 & $2(1-4)$ & 22 & $2(1-3)$ & 0.1442 \\
6 Months & 86 & $2(1-4)$ & 22 & $2(1-3)$ & 0.9967 \\
12 Months & 80 & $1(1-4)$ & 10 & $1(1-2)$ & 0.1900 \\
24 Months & 59 & $1(1-3)$ & 6 & $1(1-2)$ & 0.7818 \\
\hline
\end{tabular}

$\mathrm{BID}=$ twice daily, $\mathrm{N}=$ number of patients, $\mathrm{OD}=$ once daily. The values represent median (range)

Table 4: Daily tacrolimus dose (mg).

\begin{tabular}{|c|c|c|c|c|c|c|c|}
\hline & \multirow[b]{2}{*}{$\mathrm{N}$} & \multicolumn{2}{|c|}{ Tacrolimus BID } & \multirow[b]{2}{*}{$N$} & \multicolumn{2}{|c|}{ Tacrolimus OD } & \multirow[b]{2}{*}{ P-value } \\
\hline & & $\begin{array}{l}\text { Mean } \\
\text { (SD) }\end{array}$ & $\begin{array}{l}\text { Median } \\
\text { (Range) }\end{array}$ & & $\begin{array}{c}\text { Mean } \\
\text { (SD) }\end{array}$ & $\begin{array}{l}\text { Median } \\
\text { (Range) }\end{array}$ & \\
\hline $\begin{array}{c}1 \\
\text { Month }\end{array}$ & 91 & $2.9(1.22)$ & $3(1-6.5)$ & 23 & $2.1(1.05)$ & $2(0.5-4)$ & 0.0076 \\
\hline $\begin{array}{c}3 \\
\text { Months }\end{array}$ & 89 & $3.8(1.56)$ & $4(1-7)$ & 22 & $2.8(1.41)$ & $\begin{array}{c}2.75 \\
(0.5-5)\end{array}$ & 0.0084 \\
\hline $\begin{array}{c}6 \\
\text { Months }\end{array}$ & 86 & $3.8(1.61)$ & $4(1-7)$ & 22 & $2.8(1.57)$ & $3(0.5-6)$ & 0.0092 \\
\hline $\begin{array}{c}12 \\
\text { Months }\end{array}$ & 80 & $3.7(1.50)$ & $3.5(1-7)$ & 10 & $2.4(1.32)$ & $3(0.5-4)$ & 0.0273 \\
\hline $\begin{array}{c}24 \\
\text { Months }\end{array}$ & 59 & $3.4(1.47)$ & $3(1-6.5)$ & 6 & $1.8(0.99)$ & $\begin{array}{c}1.5(0.5- \\
3.5)\end{array}$ & 0.0065 \\
\hline
\end{tabular}

$\mathrm{BID}=$ twice daily, $\mathrm{N}=$ number of patients, $\mathrm{OD}=$ once daily, $\mathrm{SD}=$ standard deviation.
Table 5: Tacrolimus level (ng/ml)

\begin{tabular}{ccccccccc}
\hline & $\mathbf{N}$ & \multicolumn{2}{c}{ Tacrolimus BID } & N & \multicolumn{2}{c}{ Tacrolimus OD } & P-value \\
& & $\begin{array}{c}\text { Mean } \\
\text { (SD) }\end{array}$ & $\begin{array}{c}\text { Median } \\
\text { (Range) }\end{array}$ & & $\begin{array}{c}\text { Mean } \\
\text { (SD) }\end{array}$ & $\begin{array}{c}\text { Median } \\
\text { (Range) }\end{array}$ & \\
\hline 1 & 92 & $3.6(2.35)$ & $3(0.3-11)$ & 23 & 2.7 & $1.9(0.7-$ & 0.0822 \\
Month & & & & & $(1.63)$ & $7)$ & \\
3 & 87 & $6.4(3.7)$ & $6(1.3-$ & 22 & 4.4 & $3.7(0.2-$ & 0.0028 \\
Months & & & $28.5)$ & & $(3.58)$ & $15)$ & \\
6 & 83 & $6.6(2.54)$ & $6.3(1-$ & 19 & $5(2.75)$ & $4.9(0.2-$ & 0.0254 \\
Months & & & $13.7)$ & & & $9.7)$ & \\
12 & 77 & $6.5(2.81)$ & $6.2(0.5-$ & 9 & $5(3.18)$ & $4(1.5-$ & 0.0625 \\
Months & & & $13.5)$ & & & $11.8)$ & \\
24 & 55 & $6.8(3.54)$ & $6.1(0.8-$ & 5 & 5.6 & $5.2(2.1-$ & 0.5383 \\
Months & & & $16.7)$ & & $(3.28)$ & $10.5)$ & \\
\hline
\end{tabular}

$\mathrm{BID}=$ twice daily, $\mathrm{N}=$ number of patients, $\mathrm{OD}=$ once daily, $\mathrm{SD}=$ standard deviation.

Table 6: Adverse events.

\begin{tabular}{cccc}
\hline Adverse event & $\begin{array}{c}\text { Tacrolimus BID } \\
(\mathbf{N}=92)\end{array}$ & $\begin{array}{c}\text { Tacrolimus OD } \\
(\mathbf{N}=\mathbf{2 3})\end{array}$ & P-value \\
\hline New onset diabetes & $22(23.9)$ & $5(21.7)$ & 0.8259 \\
Increase in creatinine & $24(26.1)$ & $5(21.7)$ & 0.6676 \\
Dyslipidemia & $37(40.2)$ & $9(39.1)$ & 0.9242 \\
Neurotoxicity & $32(34.8)$ & $6(26.1)$ & 0.4278 \\
Hyperkalemia & $28(30.4)$ & $8(34.8)$ & 0.6876 \\
Weight gain & $22(23.9)$ & $4(17.4)$ & 0.5036 \\
\hline
\end{tabular}

$\mathrm{BID}=$ twice daily, $\mathrm{N}=$ number of patients, $\mathrm{OD}=$ once daily. The values represent number of patients (\%)

Table 7: Patient and graft survival rates

\begin{tabular}{ccccc}
\hline & N & Tacrolimus BID & N & Tacrolimus OD \\
\hline 3 Months & 92 & $89(96.7)$ & 23 & $22(95.6)$ \\
6 Months & 91 & $86(94.5)$ & 23 & $22(95.6)$ \\
12 Months & 86 & $80(93)$ & 11 & $10(90.9)$ \\
24 Months & 66 & $59(89.4)$ & 8 & $7(87.5)$
\end{tabular}

$\mathrm{BID}=$ twice daily, $\mathrm{N}=$ number of patients, $\mathrm{OD}=$ once daily.

Mean tacrolimus trough levels in the tacrolimus OD group were not significantly different from tacrolimus BID group at 1 month after transplantation. However, at 3 and 6 months after transplantation, the tacrolimus trough levels were significantly lower in the tacrolimus OD group compared to the BID group ( $\mathrm{P}=0.0028$ and 0.0254 , respectively) [Table 5]. In the present study, biopsy proven rejection was observed in $14(15.2 \%)$ patients in the tacrolimus BID group and none of the patients in the tacrolimus OD group. Eleven patients had a single episode while in 3 patients there were multiple episodes. The average time (in days) to the first, second and third rejection episode was 134.5 (range: 16-421), 253.3 (99-397) and 305 (197-413) days, respectively. Both tacrolimus BID and OD were well tolerated and the incidence of adverse events was comparable between the arms (Table 6).

In the present study, the patient and graft survival rates for tacrolimus BID and OD were comparable at 12 and 24 months (Table 7). In our study, all patients who lost the graft died since none of the patient under- 
went retransplantation. This was due to the extreme difficulty in obtaining deceased donor grafts.

\section{DISCUSSION}

The primary aim of the study was to analyse the incidence of BPAR and long term adverse events between the two formulations of tacrolimus. In our study, the incidence of BPAR was significantly lower in the tacrolimus OD group. Our results are in contrast to those of Trunecka et al ${ }^{10}$ who had reported comparable event rates of BPAR at 6 and 12 months with the tacrolimus BID and OD formulations. Our results are interesting since this lower rate of rejection in the tacrolimus OD group was despite the lower tacrolimus dose in the OD arm as compared to the BID arm. The tacrolimus trough levels in the OD arm were also significantly lower at 3 and 6 months after transplantation due to the lower dose of tacrolimus OD. Sanko-Resmer et al $^{14}$ have reported similar adequate immunosuppression of patients despite low exposure to tacrolimus, with no cases of acute rejection even though individual's minimum trough levels were below $2 \mathrm{ng} / \mathrm{ml}$ on isolated occasions.

Whether the lower level of rejection in the tacrolimus OD group is entirely due to the improved efficacy is open to debate since we did not perform pharmacokinetic and pharmacodynamic profile of the two drugs. Nevertheless, in studies, tacrolimus OD has been reported to produce lower peak concentrations and a more uniform drug level throughout its action of 24 hours compared to tacrolimus BID. ${ }^{9}$ The steady maintenance of drug concentration with OD formulation compared to the BID dosage is claimed to be the logic behind the better efficacy seen in the tacrolimus OD group. Moreover, we have analysed only BPAR rates. It is possible that there were instances of biochemical abnormalities suggestive of clinical rejection which we have not included in our definition of rejection. Often such biochemical rejection may be treated empirically by augmented immunosuppressive therapy without resorting to a liver biopsy. This may explain the reduced rejection rate in the tacrolimus OD group. Perhaps with a larger sample size and longer follow up, the difference in rejection between the groups may become less significant.

Both tacrolimus BID and OD were well tolerated and the incidence of new onset diabetes, increase in creatinine level, dyslipidemia, neurotoxicity, hyperkalemia and weight gain were comparable between the arms. Our results are consistent with those of Trunecka et al ${ }^{10}$ who had also reported comparable safety profile for both tacrolimus formulations. The incidence of diabetes $(21.8 \%$ and $21.9 \%$ in the tacrolimus BID and OD groups, respectively) and nervous system disorders like tremor and headache $(31.6 \%$ and $27 \%$ in the tacrolimus BID and OD groups, respectively) reported in their study is comparable to our results. However, the incidence of hyperkalemia and increase in blood creatinine was comparatively lower in their study (nearly $5 \%$ and $10 \%$, respectively). The DIAMOND (ADVAGRAF studIed in combinAtion with $\mathbf{M y c O}$ phenolate mofetil aND basiliximab in liver transplantation) study had reported low incidence of diabetes mellitus which may be due to the corticosteroid free maintenance protocol employed. ${ }^{15}$

In the present study, the patient and graft survival rates for tacrolimus BID and OD were comparable at 12 and 24 months. Our results are consistent with those of Trunecka et al ${ }^{10}$ who have reported $90.8 \%$ and $89.2 \%$ patient survival rates for tacrolimus BID versus OD at 12 months. The graft survival rates in their study at 12 months were $85.6 \%$ and $85.3 \%$ in the tacrolimus BID and OD groups, respectively.

In our study, 7 patients ( 4 males and 3 females) in the tacrolimus BID group and 1 male patient in the tacrolimus OD group had expired. An increased mortality rate in female liver transplant recipients with tacrolimus OD has been reported in a post hoc analysis. ${ }^{10}$ This was not observed in our study. In our study, however, the numbers were too small to derive any concrete conclusions on this aspect.
The report of the European Liver Transplant Registry has shown a significant graft survival advantage in the tacrolimus OD compared to the BID group at 3 years. ${ }^{16}$ Although, this registry suggested a trend towards improved patient survival, this was not statistically significant. It has to be mentioned that we had only 23 patients in the tacrolimus OD arm of which only 8 patients had a follow up data at 2 years. Perhaps it is too early to notice a discernible difference between the two groups in our study. Thus, it would be however interesting to follow up our patients over longer periods to investigate the long term outcomes with tacrolimus OD in the Indian set up.

Our study has several drawbacks. Firstly, it is not a randomized study, so it is possible that OD tacrolimus being a new drug, was prescribed preferentially in stable patients. Nevertheless, the pre-operative demographics and operative variables were similar in the 2 groups. Secondly, we did not perform pharmacokinetic study. Such data would have been interesting in our Indian population. Thirdly, our sample size is small, particularly in the OD tacrolimus group.

\section{CONCLUSION}

Once daily tacrolimus has a lower rate of rejection compared to twice daily formulation. This however does not translate to better long term patient or graft survival. Both the formulations when consumed for more than 3 months appear to be comparable with respect to the adverse effect and tolerability profile.

\section{CONFLICT OF INTEREST}

None

\section{ABBREVIATION USED}

BPAR: biopsy proven acute rejection, BMI: body mass index, MELD: model for end stage liver disease, OD: once daily, TD: twice daily

\section{REFERENCES}

1. Saxena R, Khan F, Masood M, Qureshi Z, Rathore M. Review on organ transplantation: A social medical need. J Crit Rev. 2016;3(2):23-9.

2. Roshni PR, Francis T. Risk factors for mortality in liver transplant recipients. Int J Pharm Sci Rev Res. 2016;40(2):68-70.

3. Song AT, Avelino-Silva VI, Pecora RA, Pugliese V, D'Albuquerque LA, Abdala E. Liver transplantation: fifty years of experience. World J Gastroenterol. 2014; 20(18):5363-74.

4. Sunny L, Emmanuel J, Krishnapriya M, Mamatha MR, Sudhindran S. Evaluation of factors influencing renal dysfunction following living donor liver transplantation. Indian J Pharm Sci. 2016;78(5):566-74.

5. US Prescribing Information of PROGRAF® (tacrolimus) capsules, USP; Astellas Pharma US, Inc.; May 2015. Available from: https://www.astellas.us/docs/ prograf.pdf

6. Patel N, Cook A, Greenhalgh E, Rech MA, Rusinak J, Heinrich L. Overview of extended release tacrolimus in solid organ transplantation. World J Transplant. 2016;6(1):144-54

7. Summary of Product Characteristics of Advagraf $0.5 \mathrm{mg}, 1 \mathrm{mg}, 3 \mathrm{mg}$ and $5 \mathrm{mg}$ prolonged-release hard capsules; Astellas Pharma Ltd; June 2015. Available from: https://www.medicines.org.uk/emc/medicine/19814

8. Posadas Salas MA, Srinivas TR. Update on the clinical utility of once-daily tacrolimus in the management of transplantation. Drug Des Devel Ther. 2014;8:1183-94.

9. Florman S, Alloway R, Kalayoglu M, Lake K, Bak T, Klein A, et al. Conversion of stable liver transplant recipients from a twice-daily Prograf-based regimen to a once-daily modified release tacrolimus-based regimen. Transplant Proc. 2005;37(2):1211-3

10. Trunecka P, Boillot O, Seehofer D, Pinna AD, Fischer L, Ericzon BG, et al. Oncedaily prolonged-release tacrolimus (ADVAGRAF) versus twice-daily tacrolimus (PROGRAF) in liver transplantation. Am J Transplant. 2010;10(10):2313-23. Erratum in: Am J Transplant. 2010;10(12):2730.

11. Beckebaum S, lacob S, Sweid D, Sotiropoulos GC, Saner F, Kaiser G, et al. Efficacy, safety, and immunosuppressant adherence in stable liver transplant patients converted from a twice-daily tacrolimus-based regimen to once-daily tacrolimus extended-release formulation. Transpl Int. 2011;24(7):666-75.

12. Dumortier J, Guillaud O, Boillot O. Conversion from twice daily tacrolimus to once daily tacrolimus in long term stable liver transplant recipients: a single 
center experience with 394 patients. Liver Transpl. 2013;19(5):529-33.

13. Ormonde DG, de Boer WB, Kierath A, Bell R, Shilkin KB, House AK, et al. Banff schema for grading liver allograft rejection: utility in clinical practice. Liver Transpl Surg. 1999;5(4):261-8.

14. Sanko-Resmer J, Boillot O, Wolf P,Thorburn D. Renal function, efficacy and safety postconversion from twice- to once-daily tacrolimus in stable liver recipients: an open-label multicenter study. Transpl Int. 2012;25(3):283-93.
15. TruneCka P, Klempnauer J, Bechstein WO, Pirenne J, Friman S, Zhao A, et al. Renal function in de novo liver transplant recipients receiving different prolonged-release tacrolimus regimens - The DIAMOND Study. Am J Transplant. 2015;15(7):1843-54.

16. Adam R, Karam V, Delvart V, Trunecka P, Samuel D, Bechstein WO, et al. Improved survival in liver transplant recipients receiving prolonged-release tacrolimus in the European Liver Transplant Registry. Am J Transplant. 2015;15(5):1267-82.

Article History: Submission Date : 11-07-2017 : Revised Date : 26-07-2017; Acceptance Date : 19-08-2017.

Cite this article: Stephen S, Ranju M, Bismi ES, Babu M, Balakrishnan D, Sudhindran S, Devi UP. A Comparative Study of Once Daily Versus Twice Daily Tacrolimus in Liver Transplantation. J Young Pharm. 2017;9(4):605-9. 